Original Research Article

\title{
Perceptions and practices of self-medication among undergraduate medical students at Gulbarga Institute of Medical Sciences, Kalaburagi, India
}

\author{
Harish G. Bagewadi, Priyadarshini M. Deodurg*, B. V. Patil, Syed Hasan Zahid
}

Department of Pharmacology, Gulbarga Institute of Medical Sciences, Kalaburagi,

Karnataka, India

Received: 30 October 2017

Revised: 03 November 2017

Accepted: 24 November 2017

\section{*Correspondence to:}

Dr. Priyadarshini M. Deodurg, Email: dr.priyadarshinideodurg @gmail.com

Copyright: (C) the author(s), publisher and licensee Medip Academy. This is an openaccess article distributed under the terms of the Creative Commons Attribution NonCommercial License, which permits unrestricted noncommercial use, distribution, and reproduction in any medium, provided the original work is properly cited.

\begin{abstract}
Background: Self-medication practice is widespread in many countries and the irrational use of drugs is a cause of concern. It assumes a special significance among medical students as they are exposed to knowledge about diseases and drugs. To assess practice and perception of self-medication among undergraduate medical students.

Methods: It is a descriptive study in which study population was comprised of $2^{\text {nd }}$ year undergraduate medical students of Gulbarga Institute of Medical Sciences, Kalaburagi, Karnataka, India. Total 134 students were included in the study. Written informed consent was obtained from each volunteer prior to the study. Students were given a questionnaire that included both open and close ended questions about self-medication practice. Data was analysed and presented as counts and percentages.

Results: It was found that $72(54 \%)$ students practiced self-medication. The principal morbidity for seeking self-medication was cold and cough as reported by $70(53 \%)$ students. Antibiotics were most commonly self-medicated as reported by $55(36 \%)$ students. Only $34(25 \%)$ students opined that selfmedication is part of self-care.

Conclusions: Self-medication is widely practiced among under- graduate medical students. In this situation, we should educate the students about advantages and disadvantages of self-medication.
\end{abstract}

Keywords: Over the counter drugs, Self-medication, Questionnaire, Perceptions, Practice

\section{INTRODUCTION}

Self-medication is the treatment of common health problems with medicines that are taken on patient's own initiative or on advice of a pharmacist, without professional supervision. It is now becoming a common practice in many countries mainly due to lack of access to health care, easy availability of OTC drugs in market and poor drug regulatory practices. ${ }^{1}$ Self-medication is the use of drugs without a doctor's advice. Medicines may be recommended by a family member or a friend or a pharmacist. Reasons for Self-medication are lack of time to see a doctor, inability to get a quick appointment, illness may be too mild and long distance away. Too much information culled from the internet or magazines make people confident about treating their own illness.

A doctor's fees may be unaffordable. The Dangers of Selfmedication are many such as habituation, allergic reactions that may be severe or even fatal. Under-dosage may not cure the symptom. Over-dosage can produce collateral damage to many organs. By masking the symptom temporarily, it will be difficult for a doctor to arrive at a 
correct diagnosis NSAID drugs like ibuprofen increase the risk of stroke. ${ }^{2}$

Unaware of the appropriate drugs for the particular illnesses, their doses, and adverse effects, the misuse of medications as prescribed by the pharmacist, or a family member, or anyone in general may lead to such people literally playing with their lives at their own mercy. But with illiteracy, there is no stop to this. On the contrary, the situation is entirely different in the case of medicos/dental or nursing students. ${ }^{3}$

Self-medication is an important health issue especially in developing countries. Various studies reported that selfmedication may lead to delay in care seeking which results in paradoxical economic loss due to delay in the diagnosis of underlying conditions and appropriate treatment. Also, self-medication can lead to interaction between drugs which would be prevented, had the patient sought care from a licensed medical practitioner. Practicing selfmedication for drugs like antibiotics might lead to drug resistance; and hence, there needs to be a check on these practices. $^{4}$

Self-medication involves the use of medicinal products by the consumer to treat self-recognized disorder or symptoms or the intermittent or continued use of medication prescribed by the physician for chronic or recurring disease or symptoms. Self-medication has number of potential risks; Incorrect self-diagnosis, failure to seek appropriate medical advice promptly, incorrect choice of therapy, failure to recognize special pharmacological risks, rare but severe adverse effects, failure to recognize or self-diagnose contraindication, interaction, warning and precaution, incorrect route and excessive dosage, risk of dependence and abuse. ${ }^{5}$

A survey conducted for first-year medical students of the Arabian Gulf University, Bahrain (including some Saudi students) suggested that these students had a poor knowledge about adequate self-medication whereas the knowledge of medication usefulness and harms was adequate. The attitude towards self-medication was positive and although the practice of self-medication was common, it was in most cases inadequate. ${ }^{6}$

The study of self-medication practice among university medical undergraduates is very important as they are a segment of the population that is highly educated and with access to information regarding their health. Looking at this practice among medical undergraduates is also very vital as they represent the future generation of drug prescribers and health educationalist. ${ }^{7}$ Self-medication was practiced with a range of drugs from the conventional anti-pains to antibiotics. Although the practice of selfmedication is inevitable; drug authorities and health professionals need to educate students about the pros and cons of self-medication. ${ }^{8}$ Self-medication result in the wastage of the resources, increase resistance of pathogens and generally cause serious health hazards such as adverse drug reaction, prolong suffering and drug dependence. ${ }^{9}$ Self-medication is a very widespread practice among students, and particularly those in medical fields. Several studies have addressed the way doctors and medical students engage in this practice. The most recent study published by Indian researchers, shows that the way they self-medicate evolves along with the increase in their knowledge. ${ }^{10}$

Only few researches have been carried out in our part of population and it is essential to study in our contest. So, we have selected this topic. Therefore, self-medication has many demerits which may directly harms to our physical as well as mental health. In this study, we will assess the perception and practices of self-medication among undergraduate medical students in a tertiary care medical college.

\section{METHODS}

The study was conducted at Gulbarga Institute of Medical Sciences, Kalaburagi. Permission was duly taken from Institutional Ethics Committee to conduct the study. It was a cross-sectional study in which study population was comprised of undergraduate medical students of Gulbarga institute of medical sciences, Kalaburagi. Total of 134 students (second year medical students) were enrolled in the study. Any event of use of over the counter (OTC) or prescription medicines without consulting a doctor were considered as self-medication. The students who took selfmedication during the last one year were included. All the students were explained about the type and purpose of the study and informed that participation is voluntary, and their collected information was not shared, and it would be anonymous. Written informed consent was obtained from each volunteer prior to the study. Students were given a questionnaire that included both open and close ended questions about self-medication practice and perceptions. The study questionnaire is obtained from minor modifications from the similar previous studies. ${ }^{10,11}$ It was reviewed by the expert faculty members. The final version of the questionnaire was distributed to the students.

\section{Statistical analyses}

Data was analysed and presented as counts and percentages.

\section{RESULTS}

It is evident that, the Perception of students regarding methods to prevent the growing trend of self-medication. Majority of the students were aware about the over the counter drugs $74(64 \%), 58(50 \%)$ were aware about generic drugs (Table 1). Out of 115 students, 55 (47\%) students aware about the side effects of the drugs. 84 (73\%) of the students were of the opinion that continuous use of the over the counter drugs can lead to addiction. 
Table 1: Awareness about various aspects of selfmedication (OTC Drug).

\begin{tabular}{|l|l|l|}
\hline Items & $\begin{array}{c}\text { Aware } \\
\mathbf{N}(\%)\end{array}$ & $\begin{array}{l}\text { Not aware } \\
\mathbf{N}(\%)\end{array}$ \\
\hline Aware about OTC drugs & $74(64)$ & $60(52)$ \\
\hline Aware about generic drugs & $58(50)$ & $76(66)$ \\
\hline $\begin{array}{l}\text { Aware about side effects of } \\
\text { drugs taken }\end{array}$ & $55(47)$ & $40(34)$ \\
\hline $\begin{array}{l}\text { Continuous use of OTC drugs } \\
\text { may cause dependency or } \\
\text { addiction }\end{array}$ & $84(73)$ & $50(43)$ \\
\hline $\begin{array}{l}\text { OTC drugs could interfere with } \\
\text { other prescribed medicines }\end{array}$ & $88(76)$ & $46(40)$ \\
\hline
\end{tabular}

Table 2: Attitude of the students towards self-medication.

\begin{tabular}{|ll|}
\hline Immediate response & N (\%) \\
\hline Self-medication part of self-care & $34(29)$ \\
\hline Start/continue self-medication & $30(26)$ \\
\hline Stop self-medication & $48(41)$ \\
\hline Advice self-medication to others & $18(15)$ \\
\hline $\begin{array}{l}\text { Self-medication of substance of abuse } \\
\text { like tobacco, Opioids and others }\end{array}$ & $2(01)$ \\
\hline
\end{tabular}

It is evident that, the students attitude the responses were more to stop Self-medication 48 (41), followed by as a part of self-care $34(29 \%)$, least was seen for the response substance of abuse like tobacco $2(01 \%)$ (Table 2).

It indicates that out of 115 respondents who practiced selfmedication, $70(60 \%)$ use medication for cold and cough, $72(62 \%)$ for fever, 35 (30\%) pain which included head, and least for the nausea and vomiting 10 (08\%) (Table 3).

Table 3: Indications for self-medication.

\begin{tabular}{|ll|}
\hline Indications & $\mathbf{N}(\%)$ \\
\hline Cold and cough & $70(60)$ \\
\hline Pain (head, body, tooth) & $35(30)$ \\
\hline Fever & $72(62)$ \\
\hline Diarrhea & $20(17)$ \\
\hline Dysmenorrhea & $18(15)$ \\
\hline Nausea and vomiting & $10(08)$ \\
\hline
\end{tabular}

Table 4: Drugs commonly used for self-medication.

\begin{tabular}{|ll|}
\hline Drugs used for self-medication & $\mathbf{N}(\%)$ \\
\hline Analgesics & $54(46)$ \\
\hline Antacids & $32(27)$ \\
\hline Antipyretics & $70(60)$ \\
\hline Antispasmodic & $15(13)$ \\
\hline Antimicrobials & $55(47)$ \\
\hline Vitamins & $40(34)$ \\
\hline Antihistamines & $42(36)$ \\
\hline Herbal & $10(8)$ \\
\hline
\end{tabular}

Drugs or drug groups are commonly used for selfmedication among 115 respondents (Table 4).

The most common drugs used are antipyretics $70(60 \%)$, antimicrobials 55(47\%), analgesics 54(46\%), antihistaminic $42(36 \%)$ and least use by herbals $10(8 \%)$. It shows that among the reasons given for self-medication. Majority $35(30 \%)$ respondents felt that they had minor illness of treating a similar illness followed by prior experience $30(26 \%), 28(24 \%)$ respondents reported that cost effectiveness was their minor reason in favour of selfmedication and for emergency use 8 (7\%) (Table 5).

Table 5: The reasons for self-medication given by respondents.

\begin{tabular}{|ll|}
\hline Reasons & N $(\%)$ \\
\hline Prior experience & $30(26)$ \\
\hline Mildness of illness & $35(20)$ \\
\hline Long waiting time & $25(21)$ \\
\hline Less costly & $28(24)$ \\
\hline Lack of interest in medical services & $12(10)$ \\
\hline In emergency use & $8(07)$ \\
\hline Others & $3(02)$ \\
\hline
\end{tabular}

It is evident that, out of 115 respondents, 75 (65\%) use sources of information as pharmacist followed by 57 (49\%) use sources of information as Internet, 50 (43\%) use advertisements, and least by text books 26 (22\%) (Table 6).

Table 6: Respondent's source of information for self-medication.

\begin{tabular}{|ll|}
\hline Sources of Information & N $(\%)$ \\
\hline Pharmacist & $75(65)$ \\
\hline Textbook & $26(22)$ \\
\hline Senior & $35(30)$ \\
\hline Advertisement & $50(43)$ \\
\hline Old prescriptions & $32(27)$ \\
\hline Friends & $44(38)$ \\
\hline Internet & $57(49)$ \\
\hline
\end{tabular}

Table 7: Perception of students regarding methods to prevent the growing trend of self-medication.

\begin{tabular}{|lc|}
\hline Immediate response & N (\%) \\
\hline $\begin{array}{l}\text { Prevent the supply of medicines without } \\
\text { prescription }\end{array}$ & $102(88)$ \\
\hline $\begin{array}{l}\text { Awareness and education regarding } \\
\text { implications of self-medication }\end{array}$ & $95(82)$ \\
\hline $\begin{array}{l}\text { Enforcing strict rules regarding } \\
\text { misleading pharmaceutical advertising }\end{array}$ & $100(86)$ \\
\hline $\begin{array}{l}\text { Working towards making health care } \\
\text { facilities easily available }\end{array}$ & $90(78)$ \\
\hline
\end{tabular}

It is shows that, the Perception of students regarding methods to prevent the growing trend of self-medication. 
Majority of the students opined that Preventing the supply of medicines without prescription 102 (88) is the main reason followed by Enforcing strict rules regarding misleading pharmaceutical advertising 100 (86), followed by Awareness and education regarding implications of self-medication 95 (82) (Table 7).

\section{DISCUSSION}

In studies conducted in India the prevalence of Selfmedication was $57.05 \%$ in West Bengal and $78.6 \%$ in Mangalore. ${ }^{12,13}$ In studies conducted in other countries, the prevalence of Self-medication was $25.4 \%$ in Ethiopia, $55 \%$ in Egypt and $55.3 \%$ in Karachi. ${ }^{14-16}$

In present study (Table 4) most of the students followed allopathic system of medicine which was similar to observations made in a study conducted in Mangalore. ${ }^{13}$ Majority of students were aware about OTC drugs and generic drugs in present study (Table 1). In a study conducted by Sontakke et al., the awareness about OTC drugs and generic drugs was higher in senior medical students. ${ }^{17}$ These factors are important because the students will be benefitted in terms of reduced cost on medicines by using generic drugs and less incidence of adverse effects if only OTC drugs are used for Selfmedication.

Only $21 \%$ students knew the side effects of drugs taken (Table 1). This shows a vital shortcoming in the knowledge of students about drugs which are selfmedicated. So, author has to work harder to make students aware of side effects of drugs which will help in reducing the incidence of side effects and also for early detection and treatment of side effects if they occur.

Most common indication for Self-medication was cold and cough in present study (Table 3) which was similar to observations made in West Bengal and southern part of India. ${ }^{12,18}$ However, fever was the most common indication for Self-medication in a study conducted in Ethiopia and Mangalore. ${ }^{13,14}$ Antibiotics were the most common class of drugs self-medicated in present study (Table 4) which was similar to observations made in west Bengal. ${ }^{12}$ However, antipyretics were the most common class of drugs self-medicated in studies from Mangalore and Ethiopia. ${ }^{13,14}$ Another study from Bahrain reported analgesics as most common class of drugs self-medicated with antibiotics contributing only $6 \%$. The reason given by researchers for limited use of antibiotics in Bahrain is that the government in Bahrain has strict regulatory policies about the prescription and over the counter sale of antibiotics. ${ }^{19}$ This suggests that the use of antibiotic is high in present study (Table 6) which could be due to lack of regulatory policy governing the OTC sale of antibiotics.

In present study $27.8 \%$ used old prescription for same illness as source of information (Table 5) about drugs which was similar to observations made in Mangalore. ${ }^{13}$ However, in another study from India and Ethiopia textbooks was the most common source of information. ${ }^{14,18}$ Majority of students self-medicated because of mild nature of illness in present study. Similar observations were made by studies from West Bengal and Nepal. ${ }^{12,20}$ In present study majority of students perceived adverse drug reactions as major disadvantage which was similar to observations made in a study from Nagpur. ${ }^{17}$ Only $29.5 \%$ students opined that Self-medication is part of self-care which was lesser to that reported in study from Mangalore. ${ }^{13}$

Self-medication has its pros and cons. Responsible Selfmedication is a convenient alternative to treat minor illness and part of self-care, whereas inappropriate Selfmedication can have harmful effects. Although OTC drugs are safe and meant for Self-medication, there can be serious implications if they are used improperly due to lack of knowledge of their side effects and interactions. So, the faculties of the institute should educate the students regarding the merits and demerits of Self-medication. The present study also perceives the implementation of regulatory control on prescription and OTC sale of antibiotics. More multicentral studies need to be carried among medical students and general population at large to study various factors influencing Self-medication. These studies should be conducted on periodic basis so that they will give insight into changing pattern of drug use in society.

Limitations of this study were based on self-reported data about Self-medication in last one year, hence recall bias cannot be ruled out. The study could have been more generalized if it was multicentral involving other medical colleges also. All the students were encouraged to fill the questionnaires independently, but mutual influence cannot be ruled out. The study did not look into as to how many students have physicians in the family so their influence as a source of prescription cannot be ruled out.

\section{CONCLUSION}

Self-medication is widely practiced among undergraduate medical students. In this situation, we should educate the students about advantages and disadvantages of Selfmedication. Steps can also be taken to the pharmacists not to provide OTC drugs. The concerned authority should only allow pharmacy graduates to sale the drugs, so that potential high risk due to drug dose, duration can be controlled to some extent.

\section{Funding: No funding sources Conflict of interest: None declared \\ Ethical approval: The study was approved by the Institutional Ethics Committee}

\section{REFERENCES}

1. Kumari R, Kiran KD, Bahl R, Gupta R. Study of knowledge and practices of self-medication among 
medical students at Jammu. J Med Sci. 2012;15(2):141-4.

2. Bell E, Dangers of Self-Medications, 2011. Available at: http://EzineArticles.com/?expert=Eva_Bell.

3. Khandelwal S, Deb D, Gonsalves J. Practice of selfmedication among medical students in Manipal. IRJPAS. 2013;3(5):175-9.

4. Kalyan VS, Sudhakar K, Srinivas P, Sudhakar GV, Pratap KV, Padma TM. Evaluation of self-medication practices among undergraduate dental students of tertiary care teaching dental hospital in South India. J Edu Eth Dent. 2013;3(1):21.

5. World Health Organization (WHO). The role of the pharmacist in self-medication and self-care.Genebra; WHO 1998. (WHO/DAO/09.13).

6. James H, Handu SS, Khaja K, Otoom SS, Sequeira RP. Evaluation of the Knowledge, Attitude and Practice of Self-medication among First-Year Medical Students. Available at: http://www.ncbi.nlm.nih.gov/pubmed/16763393.

7. Surabhi G, Meenakshi J. Study of Self-Medication Pattern In Undergraduate Students Of Subharti Medical College, Meerut (UP). J Ad Res Med Sci. 2013;5(3):266-70.

8. Abay SM, Amelo W. Assessment of Self-medication practices among medical, pharmacy, health science students in Gondar University, Ethiopia. Journal of Young Pharmacists. 2010 Jul 1;2(3):306-10.

9. Kumar P, Meena KN. Perception and practices of Selfmedication of antibiotics among undergraduate students of a medical college. Indian $\mathrm{J}$ Pharm Pharmacol. 2017;4(2);101-4.

10. Badiger S, Kundapur R, Jain A, Kumar A, Pattanshetty S, Thakolkaran N, et al. Self-medication patterns among medical students in South India. Australas Med J. 2012;5(4):217.

11. Patil SB, Vardhamane SH, Patil BV, Santoshkumar J, Binjawadgi AS, Kanaki AR. Self-medication practice and perceptions among undergraduate medical students: a cross-sectional study. JCDR. 2014;8(12):HC20.

12. Banerjee I, Bhadury T. Self-medication practice among undergraduate medical students in a tertiary care medical college, West Bengal. J Postgrad Med. 2012;58:127-31.

13. Kumar N, Kanchan T, Unnikrishnan B, Rekha T, Mithra P, Kulkarni V, et al. Perceptions and practices of self-medication among medical students in coastal South India. PloS one. 2013;8(8):e72247.

14. Abay SM, Amelo W. Assessment of Self-Medication Practices Among Medical, Pharmacy, and Health Science Students in Gondar University, Ethiopia. J Young Pharm. 2010;2:306-10.

15. El Ezz NF, Ez-Elarab HS. Knowledge, attitude and practice of medical students towards self-medication at Ain Shams University, Egypt. Journal of preventive medicine and hygiene. 2011;52(4).

16. Zafar SN, Syed R, Waqar S, Irani FA, Saleem S. Prescription of medicines by medical Students of Karachi, Pakistan: a cross-sectional study. BMC Public Health. 2008;19:162.

17. Sontakke SD, Bajait CS, Pimpalkhute SA, Jaiswal KM, Jaiswal SR. Comparative study of evaluation of self-medication practices in first and third year medical students. Int J Biol Med Res. 2011;2:561-4.

18. Badiger S, Kundapur R, Jain A, Kumar A, Pattanshetty S, Thakolkaran N, et al. Self-medication patterns among medical students in South India. Australas Med J. 2012;5:217-20.

19. James H, Handu SS, Al Khaja KA, Otoom S, Sequeira RP. Evaluation of the knowledge, attitude and practice of self-medication among first-year medical students. Med Princ Pract. 2006;15:270-5.

20. Shankar PR, Partha P, Shenoy N. Self-medication and nondoctor prescription practices in Pokhara valley, Western Nepal: a questionnaire-based study. BMC Fam Pract. 2002;3:17.

Cite this article as: Bagewadi HG, Deodurg PM, Patil BV, Zahid SH. Perceptions and practices of self-medication among undergraduate medical students at Gulbarga Institute of Medical Sciences, Kalaburagi. Int J Basic Clin Pharmacol 2018;7:63-7. 